\title{
AN EXPERIMENTAL INVESTIGATION ON MECHANICAL AND DURABILITY ASPECT DUE TO PARTIAL SUBSTITUTION OF CEMENT WITH NANO- PARTICLES
}

\author{
SNEHA KUMARI ${ }^{1}$, BEJAY YADAV ${ }^{2}$ \& SHOWMEN SAHA ${ }^{3}$ \\ ${ }^{l}$ PG Student, Department of Civil Engineering, National Institute of Technology, \\ Durgapur, West Bengal, India
}

${ }^{2}$ Research Scholar, Department of Civil Engineering, National Institute of Technology, Durgapur, West Bengal, India

${ }^{3}$ Professor, Department of Civil Engineering, National Institute of Technology, Durgapur, West Bengal, India

\begin{abstract}
This Paper investigates the impact of partial substitution of cement with nonmaterial's (Nanoclay, Graphene Nanoplatelets, Carbon Nano fibres ) on the compressive strength, water absorption and Durability of cement paste against acidic and alkaline attacks. Cement paste mixtures with various replacement ratios (i) $1 \%, 1.5 \%, 2 \%, 3 \%$ and $4 \%$ of Nanoclay (ii) $0.5 \%, 1 \%, 1.5 \%$ and $2 \%$ of Graphenenanoplatelets (iii) $0.25 \%, 0.5 \%, 0.75 \%$ and $1 \%$ of carbon nanofibres (iv) combination of two nonmaterial's i.e. (0.1\%nanoclay+ $0.1 \%$ Graphenenanoplatelets) and $(0.1 \%$ nanoclay+ $0.1 \%$ carbon nanofibre), were prepared and tested according to the standards. The results show that adding small quantities of nanomaterials could improve the mechanical strengths of cement paste. From the compressive strength test, the results show that the optimum amount of nanoclay, graphenenanoplatelets and carbon nanofibres are 3\%, $1.5 \%$ and $0.75 \%$ respectively. The compressive strength, water absorption and durability against acidic and alkaline media are also studied. KEYWORDS: Carbon Nanofibres (CNF), Cementitious Materials, Compressive Strength, Durability, Graphene Nanoplatelets (GNP), Nanoclay (NC), Water absorption
\end{abstract}

Received: May 23, 2020; Accepted: Jun 13, 2020; Published: Jun 30, 2020; Paper Id.: IJMPERDJUN2020185

\section{INTRODUCTION}

Cementitious material is widely used in the construction industry due to their easiness to fabricate, low expenditure, good performance, and versatile applications. However, the drawbacks of these cement based materials such as low tensile strength, susceptibility to cracking and likelihood of sudden failure (due to their brittle nature). Recently, the use of nanomaterials to improve the mechanical properties and durability performances of cement-based materials has received considerable attention. The small size of nanomaterials makes them distributed on a much smaller scale than other materials. It is also possible that nano filler may fill the nano-sized voids between the ingredients of cement mortar. This will limit the propagation of micro-cracks, within the cementitious materials, and lead to enhancement in the mechanical properties and other properties such as workability, consistency, water absorption and also its durability against acidic and alkaline attack.

Sen $\mathrm{Du}$ et al [1] reviewed the renewed knowledge of nano technology in cement-basedmaterials. The addition of nanomaterials in cement-based materials, associated with their dispersion in cement composites, is explored to evaluate their effects on the resistance of cement-basedmaterials to physical deteriorations, chemical deteriorations, and rebar corrosion. Di Gao et al [2] used three type of carbon nanofibres PR-19-XT-PS, PR-19-XT- 
PS-OX and PR-19-XT-LHT-OX and concluded that PR-19-XT-PS performed best at concentrations greater than 1.5\%, PR-19-XT-PS-OX performed best at concentrations around 2\% and PR-19-XT-LHT-OX performed best at concentrations around $1.0 \%$. PR-19-XT-LHT-OX performed better than the other two types of fiberstested with an $80 \%$ reduction in electrical resistance.

Chen and Chung [3] stated that, by using short pitch-based carbonfibers ( $0.5 \%$ by weight of cement $)$, together with a dispersant, chemical agents and silica fume, in concrete with fine and coarseaggregates, its compressive strength, flexural toughness and flexural strength increased by $22 \%, 205 \%$ and $85 \%$ respectively and their ductilities were also significantly improved. In addition, the dryingshrinkage and electrical resistivity were decreased by up to $90 \%$ and $83 \%$ respectively. Hughes [4] stated that by using carbon nanofibers in low carbon content flyash for rein forcement of macrodefect-free (MDF) cement, the compressive strength can increases to $334 \%$. Due to their nanosize, concrete with Nanomaterials is superior as compare to normal concrete. Baomin Wang et al [5] stated that the incorporation of $0.05 \%$ GNPs by weight of cement can enhance the flexural strength by $15 \%-24 \%$ and the compressive strength by $3 \%-8 \%$. M. S. Morsy et al [6] used 0, 2, 4, 6 and $8 \%$ nanometakaolin by weight of cement nanometakaolin and concluded that enhancement of tensile strength and compressive strength was $49 \%$ and $7 \%$ at $8 \%$ replacement and also the SEM observations confirmed that the nanometakaolin was not only acting as filler, but also as an activator to promotehydration process.

J. J. Gaitero et al [7] investigated that nanosilica increases the strength of the cement paste about $30 \%$ in cured samples and more than $100 \%$ in the asymptoticallyleachedones. A.E. AL-Salami et al [8] used 2, 4, 6, 8, 10, 12, and 14\% nanometakaolin by weight of cement and concluded that enhancement of compressive strength and flexure strength of cement paste by $50 \%$ and $36 \%$ at $10 \%$ nanoclay. M.S.Morsy et al [9] used 6\% nanometakaolin and 0.005, 0.02, 0.05 and $0.1 \%$ Carbon nanotube by weight of cement and concluded that enhancement of compressive strength of blended mortar by $18 \%$ and $29 \%$ at $6 \%$ wt. nanometakaolin and $0.02 \%$ wt. CNT scompared to control mix. M. Mazloom et al [10] used different percentage of silica fume by weight of cement and concluded that as the proportion of silica fume increased, the workability of concrete decreased but its short-term mechanical properties such as 28-days compressive strength and secant modulus improved. Also the percentages of silica fume replacement did not have a significant influence on total shrinkage.

F.T. Isfahani et al [11] concluded that at $1.5 \%$ nano silica replacement by weight, the increase in compressive strength was maximum along with improved microstructure of concrete. Byung-Wan Jo et al [12] stated that the compressive strength of nano silica concrete were higher than normal concrete at 7 and 28 days. He also described that nano silica behave not only as a filler to improve micro structure but also as an activator to promote pozzolanic reaction. Tao Ji [13] investigated that the nano silica concrete is sticker than normal concrete due to large specific area and also nano silica concrete possess better water permeability resistance behaviour than normal concrete.

M. Khanzadi et al [14] concluded that by addition of nano silica, compressive and tensile strength of the concrete got enhanced.They stated that nano silica addition could improve microstructure of cement paste and also better resistance against permeability because these particles provide a more uniform distribution in the microstructure of concrete.

$\mathrm{H}$. Li et al [15] concluded that the compressive and flexural strength was higher for nano silica concrete than that of normal concrete after 28 days. The presesnt research is thus aimed at investigating the effect of nonmaterials i.e. 
Nanoclay, Graphene Nanoplatelets, Carbon Nanofibres on the Compressive strength, Water absorption and Durability of cement paste again stacidic and alkaline attacks.

\section{EXPERIMENTAL WORK}

This experimental work was performed to find out the compressive strength, water absorption and durability against acidic and alkaline media of cement paste and cement paste containing different percentage of Nano materials.

\section{Material Used}

The materials used in this study were Portland slag cement, Nanoclay surface modified-contains $25-30 \%$ wt.trimethyl stearyl ammonium(NC), Carbon nanofibres-graphitized(iron-free),composed of conical platelets, D $\times \mathrm{L} 100 \mathrm{~nm} \times 20$ -

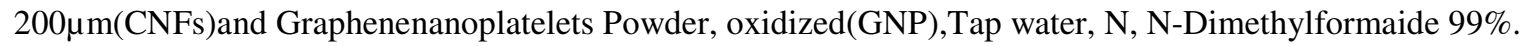

\section{Cement}

Portland slag cement (slag based) conforming to IS:455 was used in the present experimental work. The various laboratory tests confirming to IS: 4031-1988 (PART 2,3 and5) specification was carried out as tabulated below:

Table 1: Properties of Cement

\begin{tabular}{|c|c|}
\hline Fineness & $\geq 225 \mathrm{~m}^{2} / \mathrm{kg}$ \\
\hline Initial Setting Time & $\geq 30$ minutes \\
\hline Final Setting Time & $\leq 600$ minutes \\
\hline Specific Gravity & $2.85-2.94$ \\
\hline
\end{tabular}

\section{Carbon Nano-Fibres}

Carbon nanofibers are discontinuons, highly graphitic, highly compatible with most polymer processing techniques and can be dispersed in an mechanical properties, high electrical conductivity, and high thermal conductivity, which can be imparted to a wide range of matrices including thermo plastics, thermo sets, elastomers, ceramics, and metals. Carbon nanofibersalso have a unique surface state, which facilitates fonctionnalisation and other surface modification techniques to engineer the nanofiber to the host polymer.

Table 2: Properties of Carbon Nano-fibres

\begin{tabular}{|l|c|}
\hline Appearance (Color) & Black \\
\hline Appearance (Form) & Powder \\
\hline X-Ray Diffraction & Conforms to Structure \\
\hline Iron (Fe) & $\leq 100 \mathrm{ppm}$ \\
\hline
\end{tabular}

\section{Nano-Clays}

Nano clays are clay minerals which have a high aspect ratio. At least one dimension of the particle should be in the nanometer range. Nanoclays are a broad class of naturally occurring inorganic minerals. Montmorillonite i.e. plate like structure is the most commonly used in materials applications. It consists of $\sim 1 \mathrm{~nm}$ thick aluminosilicatelayers surfacesubstituted with metal cations and stacked in $\sim 10 \mu \mathrm{m}$-sized multilayer stacks .Its critical characteristics are purity and cation exchange capacity. Its purity is important in achieving maximum increases in mechanical properties and also achieving optimum clarity for use in films. Impurities in materials act as stress concentrators, resulting in poor impact and tensile properties. 
Table 3: Properties of Nano-clays

\begin{tabular}{|l|c|}
\hline Appearance (Color) & Off White to Beige \\
\hline Appearance (Form) & Powder \\
\hline Loss on Drying & $\leq 6 \%$ \\
\hline Bulk Density & $200-500 \mathrm{~kg} / \mathrm{m} 3$ \\
\hline Average Particle Size & $\leq 20$ micron \\
\hline
\end{tabular}

\section{Graphene Nano-Platelets}

Graphene Nanoplatelets consist of small stacks of graphene that can replace carbon fiber, carbon nanotubes, Nano-clays,or other compounds in many composite applications. When they are added at 2-5\%wt.to plastics or resins they make these materials electrically or thermally conductive and less permeable to gasses, while simultaneously improving mechanical properties like strength, stiffness, or surface toughness. The GNPs that all have the same image are the plasma exfoliated products.

Table 4: Properties of Graphene Nano-platelets

\begin{tabular}{|l|c|}
\hline \multicolumn{1}{|c|}{ Appearance (Color) } & Grey to Black \\
\hline Appearance (Form) & Powder \\
\hline X-Ray Diffraction & Conforms to Structure \\
\hline Carbon $(\mathrm{C})$ & $\geq 95 \%$ \\
\hline Oxygen $(\mathrm{O})$ & $\geq 1 \%$ \\
\hline
\end{tabular}

\section{Cement Paste Preparation}

The cement paste was prepared using Portland slag cement and water/cement ratio of 0.45 . The cement paste was prepared using Portland slag cement that was partially substituted by nanomaterials. Nanomaterials was first ultra-sonicated with the aid of water and the surfactant. The desired amount of Nanomaterials was added to the water together with surfactant and then hand-stirred for 1 minute. After that the aqueous solution placed in sonicator for 2 hours, then mixed into cement and prepared cement paste. The cement pastes were moulded into 50mm cubes. The moulds filled with cement paste were vibrated for one minute to remove any air bubbles. The samples were kept in moulds for 24 hours, and then cured in water for 28 days and 56 days.

\section{TEST RESULTS}

The tests were conducted on Hardened Cement paste. The compressive strength, water absorption and durability tests against acidic and alkaline media conducted on hardened cement are briefed here:

\section{Compressive Strength Test}

The compressive strength test was carried out on cube specimens of dimensions $50 * 50 * 50 \mathrm{~mm}$. The compressive strength test specimens were cured and tested for 28-days and 56-days in universal testing machine. Three specimens were used for each test. The test results are shown below: 
Table 5: Compressive Strength Test Results

\begin{tabular}{|l|c|c|c|c|}
\hline \multirow{2}{*}{ Mix Designation } & \multicolumn{2}{|c|}{ 28 Days } & \multicolumn{2}{c|}{ 56 Days } \\
\cline { 2 - 5 } & $\begin{array}{c}\text { Compressive } \\
\text { Strength (mpa) }\end{array}$ & $\begin{array}{c}\text { Enhancement } \\
(\%)\end{array}$ & $\begin{array}{c}\text { Compressive } \\
\text { Strength (mpa) }\end{array}$ & $\begin{array}{c}\text { Enhancement } \\
(\%)\end{array}$ \\
\hline C & 18.84 & 0.00 & 19.632 & 0.00 \\
\hline C-1\%NC & 19.72 & 4.67 & 20.560 & 4.73 \\
\hline C-1.5\%NC & 20.88 & 10.80 & 21.704 & 10.55 \\
\hline C-2\%NC & 22.12 & 17.41 & 23.00 & 17.15 \\
\hline C-3\%NC & 23.68 & 25.69 & 24.40 & 24.28 \\
\hline C-4\%NC & 18.48 & -1.91 & 19.20 & -2.20 \\
\hline C-0.25\%CNF & 20.08 & 6.58 & 21.84 & 11.25 \\
\hline C-0.5\%CNF & 21.20 & 12.52 & 22.082 & 12.48 \\
\hline C-0.75\%CNF & 24.50 & 30.04 & 25.84 & 31.62 \\
\hline C-1\%CNF & 17.56 & -6.70 & 18.822 & -4.12 \\
\hline C-0.5\%GNP & 25.36 & 34.6 & 26.32 & 34.06 \\
\hline C-1\%GNP & 27.76 & 47.34 & 29.082 & 48.13 \\
\hline C-1.5\%GNP & 29.84 & 58.38 & 32.416 & 65.11 \\
\hline C-2\%GNP & 18.72 & -0.64 & 19.532 & -0.51 \\
\hline C-0.1\%NC+0.1\%CNF & 31.08 & 64.96 & 31.72 & 61.57 \\
\hline C-0.1\%NC+0.1\%GNP & 36.52 & 93.84 & 37.88 & 92.95 \\
\hline
\end{tabular}

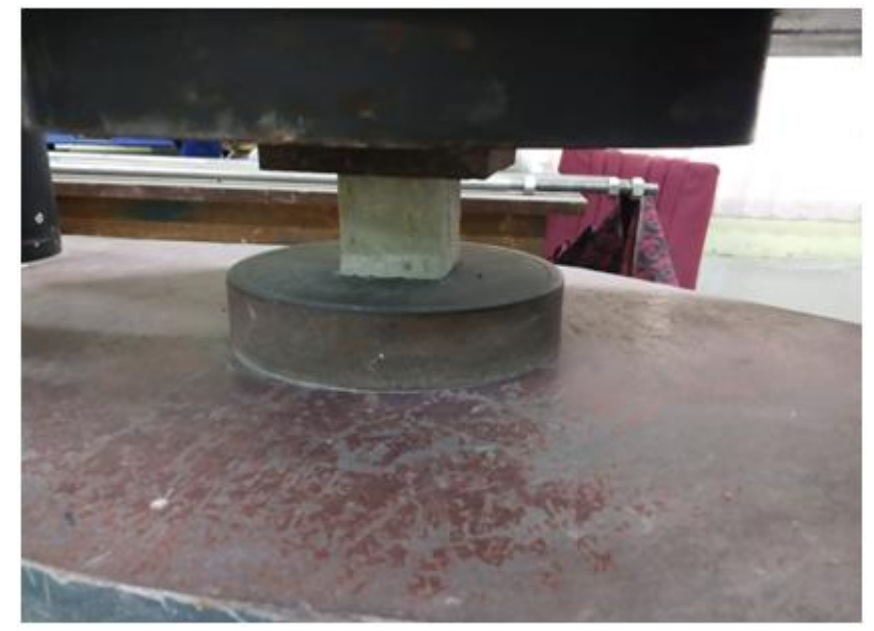

Figure 1: Compressive Test Setup.

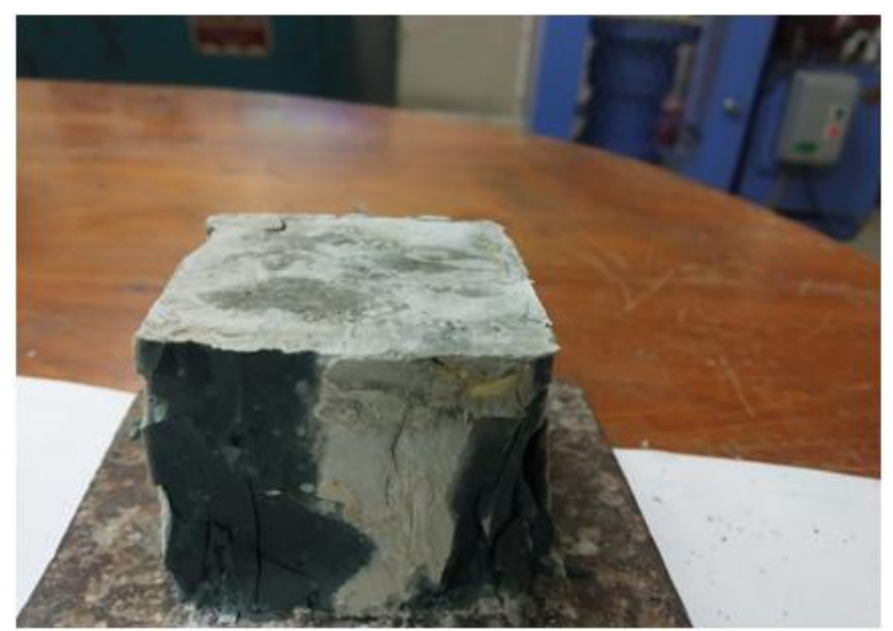

Figure 2: Failedspecimen. 


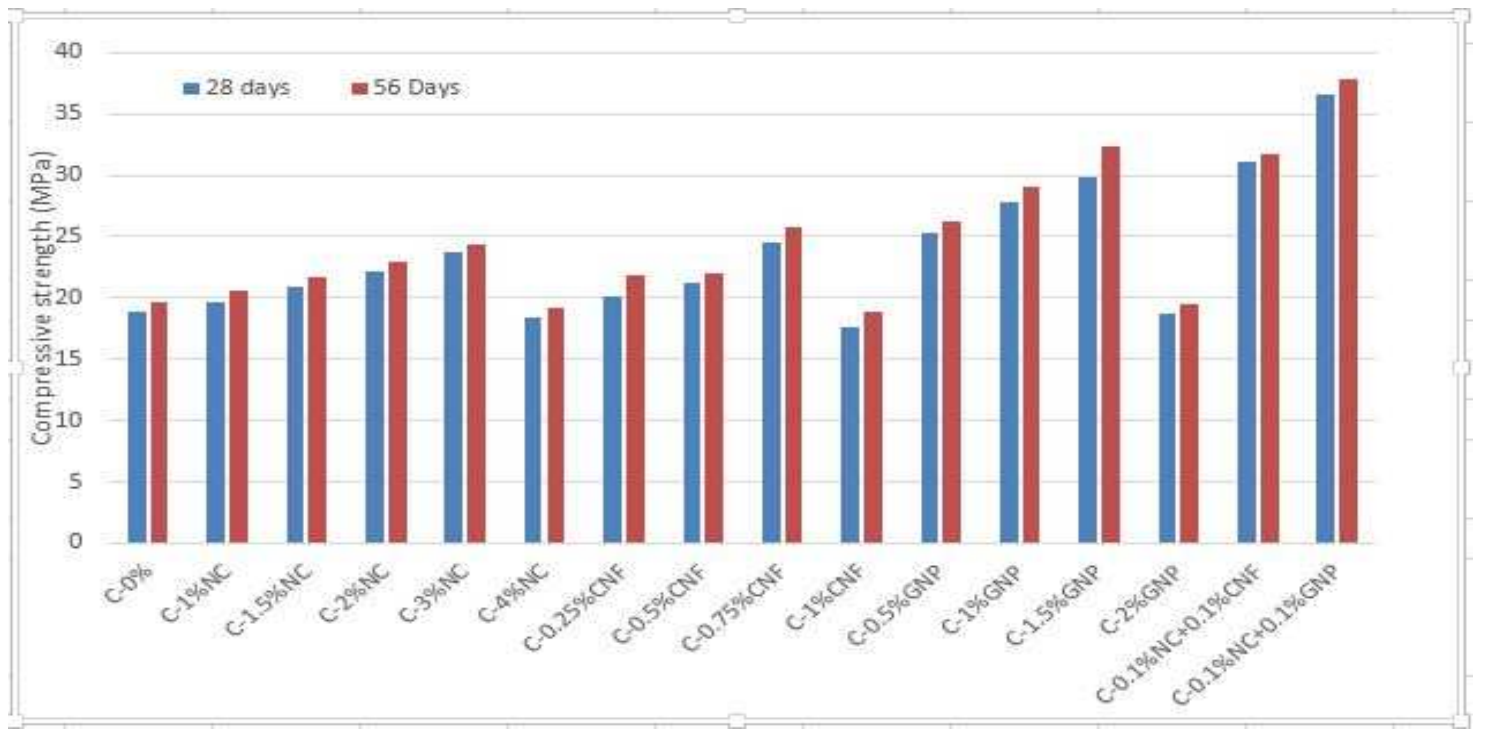

Figure 3: Compressive Strength Test Results.

\section{Water Absorption}

Three specimens of each batch were cast then wet cured for 28days. The cured-specimens were then dried to a constant mass and weighed. The dry-specimens were instantly immersed in a curing tank for different periods of time. Then the samples were collected from the curing tank, wiped to remove the excess water from the surface and weighed again. The water absorption was calculated from the difference in the mass of the specimen before and after immersing them in water. The test results after 28 and 56 days are shown below:

Table 6: Water Absoprtion Test Results

\begin{tabular}{|l|c|c|}
\hline Mix Designation & After 28 Days (\%) & After 56 Days (\%) \\
\hline C-0\% & 2.3 & 2.9 \\
\hline C-1\%NC & 1.0 & 1.5 \\
\hline C-2\%NC & 0.8 & 1.3 \\
\hline C-3\%NC & 0.4 & 0.7 \\
\hline C-4\%NC & 0.1 & 0.2 \\
\hline C-0.5\%CNF & 0.0 & 0.0 \\
\hline C-1\%CNF & 0.0 & 0.0 \\
\hline C-0.5\%GNP & 0.0 & 0.0 \\
\hline C-1\%GNP & 0.0 & 0.0 \\
\hline
\end{tabular}

\section{Durability Test Resistance against Acidic Media}

For acid attack test cement cube of size $50 * 50 * 50 \mathrm{~mm}$ are prepared for various percentages of nanomaterials. The specimen were casted and cured in mould for 24 hours, then were demoulded and kept in curing tank for 7-days. After 7days all specimens were kept in atmosphere for 2-days to achieve a constant weight. Subsequently, the specimens were weighed and immersed in 5\% sulphuric acid solution for 60-days. The $\mathrm{pH}$ value was periodically checked and maintained at 3. After 60-days of immersing in acid solution, the specimens were taken out and washed in running water and kept in atmosphere for 2-days to achieve a constant weight. Subsequently the specimens were weighed and the percentage loss of weight was calculated for each specimen.Table 7 shows the change in weight of control specimen and cement containing Nanomaterials specimen when immersed in 5\% Sulphric acid $\left(\mathrm{H}_{2} \mathrm{SO}_{4}\right)$ solution. Table 8 Shows the compressive strength of 

due to Partial Substitution of Cement with Nano-Particles

specimen after 60 days. The results showed that by adding nanomaterials durability of cementitious materials against acidic media also increases.

Table 7: Durability Test against Acidic Media Results

\begin{tabular}{|l|c|}
\hline Mix Desgination & Average Percentage of wt Loss in Acidic Media After 60 Days \\
\hline C-0\% & 1.9 \\
\hline C-0.25\%CNF & 1.5 \\
\hline C-0.5\%CNF & 1.2 \\
\hline C-0.75\%CNF & 1.0 \\
\hline C-1\%CNF & 0.8 \\
\hline C-0.5\%GNP & 1.3 \\
\hline C-1\%GNP & 1.1 \\
\hline C-1.5\%GNP & 0.7 \\
\hline C-2\%GNP & 0.5 \\
\hline
\end{tabular}

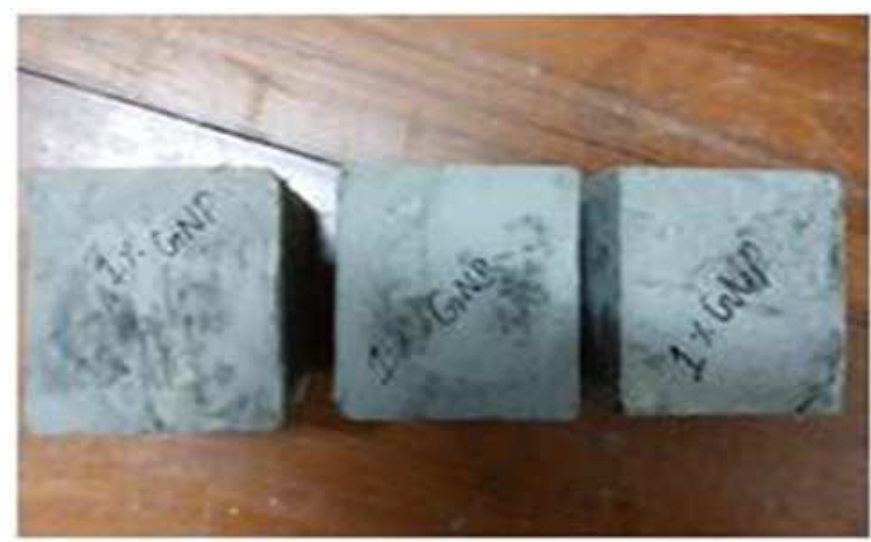

Figure 4: Test Specimen Before Acid Attack.

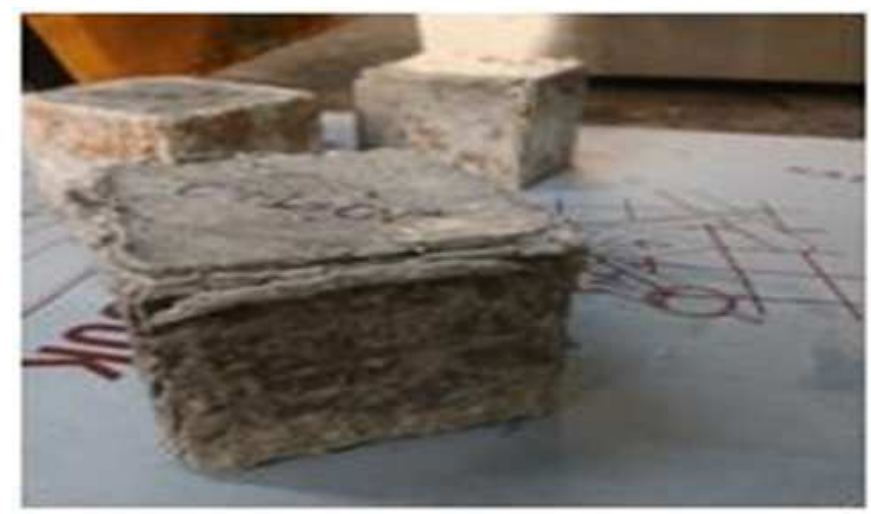

Figure 5: Test Specimen After Acid Attack.

Table 8: Compressive Strength Against Acidic Media

\begin{tabular}{|l|c|c|}
\hline Mix Desgination & $\begin{array}{c}\text { Comp Strength } \\
\text { (60 Days) }\end{array}$ & $\begin{array}{c}\text { Enhancement } \\
(\%)\end{array}$ \\
\hline C & 15.96 & 0.0 \\
\hline C-0.25\%CNF & 18.22 & 14.2 \\
\hline C-0.5\%CNF & 20.22 & 26.7 \\
\hline C-0.75\%CNF & 23.84 & 49.4 \\
\hline C-1\%CNF & 15.48 & -3.0 \\
\hline C-0.5\%GNP & 19.52 & 22.3 \\
\hline C-1\%GNP & 20.36 & 27.6 \\
\hline C-1.5\%GNP & 23.97 & 50.2 \\
\hline C-2\%GNP & 15.87 & -0.6 \\
\hline
\end{tabular}




\section{Durability Test Resistance against Alkaline Media}

For alkaline attack test cement cube of size $50 * 50 * 50 \mathrm{~mm}$ are prepared for various percentages of Nanomaterials. The specimen were casted and cured in mould for 24 hours, then were demoulded and kept in curing tank for 7-days. After 7days all specimens were kept in atmosphere for 2-days to achieve a constant weight. Subsequently, the specimens were weighed and immersed in 5\% sodium sulphate solution for 60-days. The $\mathrm{pH}$ value was periodically checked and maintained at 12. After 60-days of immersing in alkaline solution, the specimens were taken out and washed in running water and kept in atmosphere for 2-days to achieve a constant weight. Subsequently the specimens were weighed and loss in weight and hence the percentage loss of weight was calculated.From the experiment it shows that percentage of weight loss in alkaline media after 60 days is zero. Table 9 shows the compressive strengthof specimen after 60 days. The results showed that by adding Nano materials durability of cementitious materials against alkaline media also increases.

Table 9: Compressive Test Result against Alkaline Media

\begin{tabular}{|l|c|c|}
\hline \multicolumn{1}{|c|}{ Mix Desgination } & $\begin{array}{c}\text { Comp. Strength (60 } \\
\text { Days) }\end{array}$ & Enhancement (\%) \\
\hline C & 19.82 & 0.0 \\
\hline C-0.25\%CNF & 22.56 & 13.82 \\
\hline C-0.5\%CNF & 23.85 & 20.33 \\
\hline C-0.75\%CNF & 26.04 & 31.38 \\
\hline C-1\%CNF & 18.24 & -7.97 \\
\hline C-0.5\%GNP & 24.76 & 24.92 \\
\hline C-1\%GNP & 27.82 & 40.36 \\
\hline C-1.5\%GNP & 29.32 & 47.93 \\
\hline C-2\%GNP & 19.76 & -0.30 \\
\hline
\end{tabular}

\section{CONCLUSIONS}

In this study experiment were conducted for Cement Paste and Cement Paste along with Nanomaterials to find and compare their Compressive strength, water absorption and durability against acidic and alkaline media. Compressive strength tests and water absorption tests were performed for each combination of both for 28 days and 56 days respectively. Durability test resistances against acidic and alkaline media were performed for each combination for 60Days strength.

- The results obtained in the first trial (i.e., Cement with $0.1 \%$ NC \& $0.1 \%$ GNP) were satisfactory and clearly indicated that the strength got enhanced (93.84\% for 28 days strength and $92.95 \%$ for 56 days strength) by introduction of $0.1 \% \mathrm{NC} \& 0.1 \%$ GNP.

- The results obtained in the second trial (i.e., Cement with $0.1 \% \mathrm{NC} \& 0.1 \% \mathrm{CNF}$ )were also satisfactory and the strength got enhanced(64.96\% for 28 days strength and $61.57 \%$ for 56 days strength) by introduction of $0.1 \% \mathrm{NC}$ $\& 0.1 \% \mathrm{CNF}$

- The results obtained in the further trial (i.e., Cement with $1 \%, 1.5 \%, 2 \%, 3 \% \mathrm{NC}$ ) were satisfactory and its strength got enhanced by $4.67 \%, 10.8 \%, 17.41 \%, 25.69 \%$ consecutively after 28 days and $4.73 \%, 10.55 \%, 17.15 \%, 24.28 \%$ consecutively after 56 days. But Cement with $4 \% \mathrm{NC}$, its strength decreased by $1.91 \%$ after 28 days and $2.2 \%$ after 56 days. Thus, best results obtained at 3\% NC. And water absorption test results show that its value decreases by increasing percentage of nanoclay after 28 days and 56 days. 
- The results obtained in the further trial (i.e., Cement with $0.25 \%, 0.5 \%, 0.75 \% \mathrm{CNF}$ ) were satisfactory and its strength got enhanced by $6.58 \%, 12.52 \%, 30.04 \%$ after 28 days and $11.25 \%, 12.48 \%, 31.62 \%$ after 56 days. But Cement with $1 \% \mathrm{CNF}$, its strength decreased by $6.70 \%$ after 28 days and $4.12 \%$ after 56 days. Thus, best results obtained at $0.75 \% \mathrm{CNF}$.

- The results obtained in the further trial (i.e., Cement with $0.5 \%, 1 \%, 1.5 \% \mathrm{GNP}$ ) were satisfactory and its strength got enhanced by $34.6 \%, 47.34 \%, 58.38 \%$ consecutively after 28 days and $34.06 \%, 48.13 \%, 65.11 \%$ after 56 days. But Cement with $2 \%$ GNP, its strength decreased by $0.64 \%$ after 28 days and $0.51 \%$ after 56 days. Thus, best results obtained at $1.5 \% \mathrm{GNP}$.

- Water absorption test results showed that by adding nanoclay its value decreased by increasing percentage of nanoclay. But in case of CNF and GNP its value became zero by adding $0.5 \%$ and $1 \%$ after 28 days and 56 days.

- The results obtained from durability test resistance against acidic and alkaline media were satisfactory and its strength also increased by adding GNP and CNF.

\section{ACKNOWLEDGEMENTS}

Authors are greatful to National Institute of Technology Durgapur for providing laboratory facilities to carry out this research work.

\section{REFERENCES}

1. Sen Du, Junliang Wu, Othman Alshareedah and Xianmingshi, "Nanotechnology in Cement-Based Materials: A Review of Durability," Department of Civil and Environmental Engineering, Washington State University, Pullman, WA 99164-2910, USA.

2. Di Gao, Mariel Sturm and Y L Mo, "Electrical resistance of carbon-nanofiber concrete,"Article in smart Materials and structures20(4) · April 2011

3. Pu-Woeichen, D D L Chung, "Concreterein forced with up to 0.2 vol\% of short carbon fibres," Composites Volume 24, Issue 1,1993, Pages 33-52.

4. Hughes, Thomas, "Fly Ash Enhanced Carbon Naonfibre-Reinforced High Strength Cement," Ohio Air Quality, Vers. Final Report. Dec.2004.Ohio Coal Development Office.5 Sept. 2008.

5. Baomin Wang, Ruishuang Jiang and Zhenlin Wu, "Investigation of the Mechanical Properties and Microstructure of Graphene Nanoplatelet-Cement Composite," Nano materials (Basel). 2016 Nov; 6(11): 200.Published online 2016 Nov 4. doi: 10.3390/nano6110200.

6. M. S. Morsy, S. H. Alsayed and M. Aqel, "Effect of Nano-clay on Mechanical Properties and Microstructure of Ordinary Portland Cement Mortar," International Journal of Civil \& Environmental Engineering IJCEE-IJENS Vol: 10 No: 01.

7. J. J. Gaitero, I. Campillo, \& A. Guerrero, "Reduction of the Calcium leaching rate of cement paste by addition of silica nanoparticles. Cement and Concrete Research,Volume 38, Issues 8-9,August 2008,pages 1112-1118.

8. A.E.AL-Salami, H. Shoukry, M.S. Mosy, "Thermo-Mechanical Characteristics of Blended White Cement Pastes Containing Ultrafine Nano Clays," Int. J. Green Nanotecnology: Biomed.4(4) (2012)516-527.

9. M.S. Morsy, S.H. Alsayed, M. Aqel, "Hybrideffect of carbon nanotube and nano-clay on physico-mechanical properties of cementmortar," Construction and Building Materials 25(1) (2011) 145-149. 
10. M. Mazloom, A. A. Ramezanianpour, J. J. Brooks, "Effect of silica fume on mechanical properties of high-strength concrete," cement and concrete composities, 26(4)(2004) 347-357.

11. F. T. Isfahani, E. Redaelli, F. Lollini, W. Li, and L. Bertolini, "Effects of nano silica on compressive strength and durability properties of concrete with different water to binder ratio," vol. 2016, 2016.

12. Byung-Wan Jo, Chang-Hyun Kim, Ghi-ho Tae, Jong-Bin Park, "Characteristics of cement mortar with nano-SiO ${ }_{2}$ particles," Construction and Builiding Materials, Volume 21, Issue 6,2007,pp. 1351-1355.

13. Tao J I, "Preliminary study on the water permeability and microstructure of concrete incorporating nano-SiO ${ }_{2}$," Cement and Concrete Research, 35, 1943-1947.

14. J. June, U. Politecnica, M. Khanzadi, M. Tadayon, H. Sepehri, and M. Sepehri, "Influence of Nano-Silica Particles on Mechanical Properties and Permeability of Concrete," 2010.

15. H. Li, H.G. Xiao, J.P. Ou," A study on mechanical and pressure- sensitive properties of cement mortar with nanophase materials," Cement and Concrete Research 34 (3) (2004) 435-438.

16. Sing, Jagmeet, and Jaspal Singh. "Sustainable Use of Industrial Waste in Cement Industry." International Journal of Environment, Ecology, Family and Urban Studies (IJEEFUS) 6.3 (2016): 45-54.

17. Srinivas, Kurapati. "Nanomaterials for concrete technology." International Journal of Civil, Structural, Environmental and Infrastructure Engineering Research and Development (IJCSEIERD) 4.3 (2014): 79-90.

18. George, Raiza Susan, and Nivin Philip. "A Review on Stress Block Parameters of High Performance Concrete." International Journal of Civil Engineering (IJCE) 5.6 (2016) : 25-32

19. Singh, Saurabh Kumar, et al. "A Review on Effect of Mineral Admixture on Self Compacting Concrete." International Journal of Civil Engineering (IJCE) 3.3 (2014) : 79-90

20. Rajagopal, Deepthy, and Mathews M. Paul. "Durability study of self-compacting concrete using manufactured sand." IMPACT: International Journal of Research in Engineering \& Technology (IMPACT: IJRET) 2.9 (2014): 45-50.

21. Patel, Vatsal, and Niraj Shah. "Durability-Key Factor of New Generation Concrete Preparations." International Journal of Civil, Structural, Environmental and Infrastructure Engineering Research and Development (IJCSEIERD) 4.5 (2014) : 25-30 